Journal (Sorsby, 1939). The fundi in two brothers whose eye trouble dated back to the early twenties showed a sharplycircumscribed central area in which the choroidal vessels were sclerosed. It is suggested that these cases of choroidal sclerosis are allied to macular coloboma-coloboma on the one hand and " senile" macular degeneration due to choroidal sclerosis on the other, representing the two extremes of a continuous range of dystrophy in which the two cases of central choroidal sclerosis with onset in early life form a connecting link.

Our thanks are due to Dr. A. D. Morris, Medical Superintendent of St. Leonard's (L.C.C.) Hospital and to Dr. K. S. May for the trouble they have taken to obtain the eye for examination.

\title{
RERERENCES
}

The literature is cited in SORSBY, A. (1935). The following are additional references: JANKU, J,-Casopis lekarew ceskyck, Vol. LXII, p. 1021, 1923. A full abstract of this paper published in Czech appears in the article by Wolf and Cowen.

Rintelen, F.-Klin. Monatsbl. f. Augenheilk., Vol. XCIII, p. 113, 1934.

SorsBY, A.-Brit. Jl. Ophthal., Vol. XIX, p. 65, 1935.

Ibid., Vol. XXIII, p. 433, 1939.

WeXler, D., and LAST, M.-A rch. of Ophthal., Vol. XX, p. 787, 1938.

Wolf, A., and CoweN, D.-Bull. Neurol. Inst., New York, Vol. VI, p. 351, 1937.

\section{THE OPHTHALMOLOGICAL COMPLICATIONS OF LEONTIASIS OSSEA}

\author{
BY \\ Seymour. Philps
}

LONDON

LEONTIASIS was the name given to certain forms of leprosy of the face, in which disease the thickened, seamed lips give the appearance of a lion's muzzle. In 1896, the name "leontiasis ossea " was coined by Virchow to describe a group of diseases which cause hyperostosis of the skull and facial bones. Specimens in many museums showed what different shapes these skulls might assume, but it was not until 1923 that any classification was attempted. In that year, Mr. Lawford Knaggs published an article in the British Journal of Surgery which is still the final word on the subject, and it is from that article that much of the information and three of the pictures reproduced here are obtained.

It is now clear that there are two types of hyperostosis :-

1. Creeping periostitis of the bones of the face and skull.

2. Diffuse osteitis of the bones of the face and skull.

$a$. General. b. Circumscribed. c. Local. 
Creeping periostitis of the bones of the face and skull.-This condition most commonly affects the bones of the lower jaw, and has its origin from an infected tooth. It is possible for it to spread from the lower jaw over the bones of the face and cranial vault, leaving exuberant masses of compact bone in its path, which masses are densely opaque to X-rays, and of an ivory hard consistence. The ophthalmological interest of this type lies in the fact that in several instances it has started at the inner aspect of one or both orbits as a result of suppuration in the lacrimal sac. Virchow quotes the following case :-

A boy of twelve, the son of a surgeon named Fourcade at Perpignan, had a tumour of the right lacrimal sac which was opened by his father. It continued to suppurate for a very long time, and a bony tumour arose from the nasal portion of the right superior maxilla, which at the age of fifteen years compressed the right side of his nose so that it was difficult for him to breathe. It spread over both sides of his face until, five years

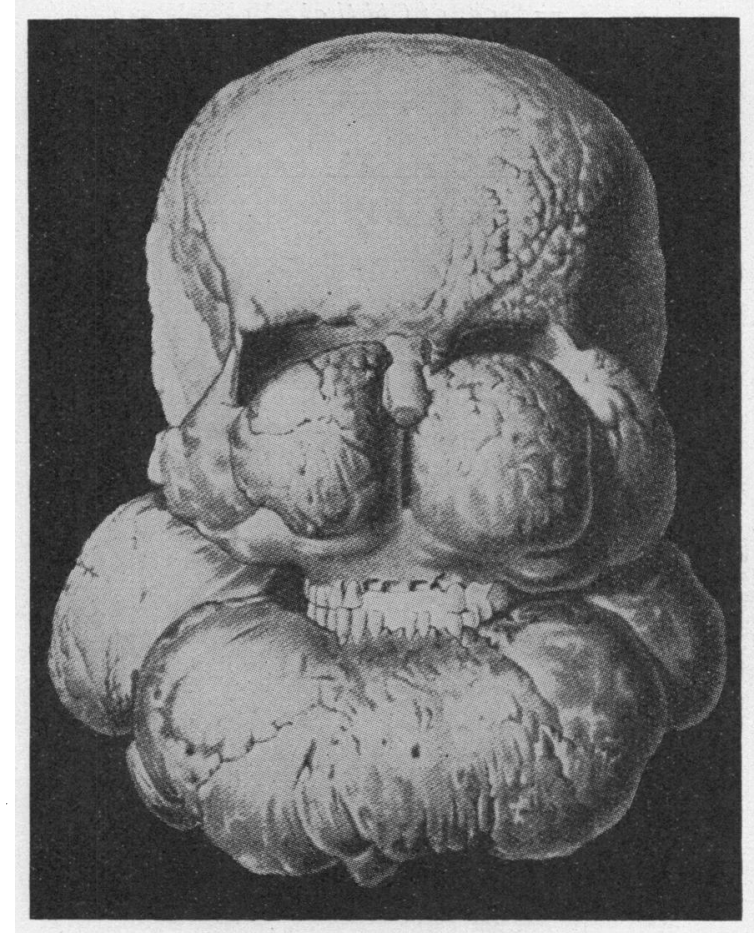

Fig. 1.

Fourcade's case. By kind permission of R. Lawford Knaggs. 
later, "the face was monstrous and there was exophthalmos, myopia, and difficulty in speaking." He died, blind and phthisical at the age of forty-five and a picture of the skull will be seen in Fig. 1.

Another instance of this type of tumour is given by John Howship (Observations in Surgery, 1819). Howship examined a man who was then sixty years old, and goes on to tell how :-

" About fourteen years back he was walking up Hampstead Hill on a windy day, when he was attacked by a violent itching and heat in both his eyes. Before he could reach home he was unable to open his eyes in the light. Inflammation supervened, and a small tumour formed just below the inner angle of each eye, about the size of a hazel nut. These swellings burst inwardly, discharging freely between the eyelids. The inflammation was treated with poppy heads and fomentations, and went on for about twelve weeks, after which it subsided and he was able to go to work. A fortnight later he took a fresh cold, and on this occasion he applied to an eminent oculist, Mr. Ware, who ordered him to lay a warm poultice over each eye, as the swellings were again returning. About six weeks later both abscesses burst upon the cheek. The formation of these abscesses was attended with pain in the head the severity of which he could compare to nothing but the sensation of his head splitting asunder. For three months he was never free from the most insupportable and horrid pains in and about his head. He was advised to go into St. Bartholomew's Hospital, where he remained six weeks without anything material having been done. An operation had been proposed to him, which he did not choose to submit to, and he was consequently discharged from the House. There was now a considerable projection of tumour, apparently ossific, below the inferior margin of each orbit, the eyes being rendered more prominent than they are naturally.

The case excited much attention while in hospital, and one day one of the young gentlemen, observing the right eye, thrust out from the orbit, on pushing back the eyelid the globe of the eye suddenly sprung out beyond the palpebrae, and it was with some difficulty reduced again. At this time he had the power of perceiving light with the right but more with the left eye. $\mathrm{He}$ was often very delirious, and was subsequently informed that it was sometimes with extreme difficulty that he was prevented from tearing his eyes out in the rage of pain and delirium. In the course of an attack, the right eye burst from the intensity of the inflammation. The contents of the eyeball being effused, the excessive inflammation declined, and he became somewhat better. Sometime after his return home from hospital, he was putting down a turn-up bed, and not being able to see what he was about, 
the bedstead slipped from his hand and fell, one of the feet striking him with great force upon the ball of the eye that was protruded, and lying upon the hard tumour in the cheek. By this accident the globe of the left eye was burst."

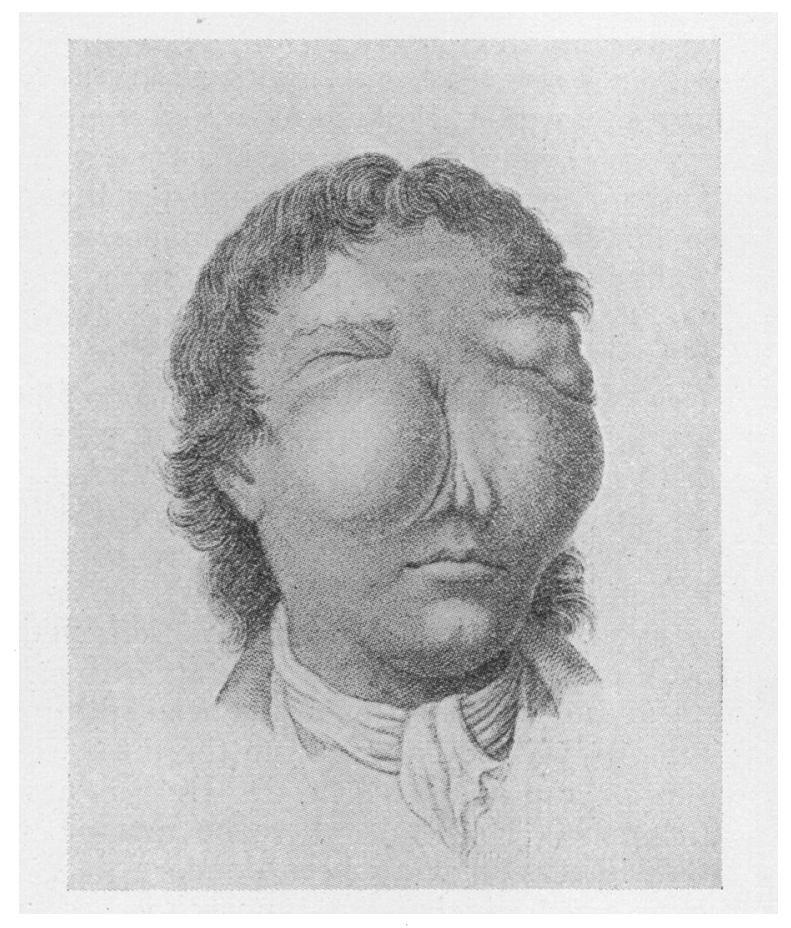

FIG. 2.

Howship's patient (after Howship).

In 1815 he remained well, but eventually died of an effusion of blood beneath the arachnoid. His skull may be seen in the Royal College of Surgeon's Museum, General Pathology Section, No. 1357.1 and Fig. 2, taken from Howship's book shows his appearance towards the end of his life.

Von Paas also describes a case of this type, and states that the pressure on the globes was such that one eye was destroyed, but the sight of the other had so far been preserved by trephining. This is the most recent case of this type that I can find in the literature, and think they are unlikely to occur at the present time, when lacrimal and other forms of suppuration are not allowed to continue for such long periods as in Howship's day. Should they occur, it is probable that the resources of modern surgery would prevent the disastrous consequences here described. 
Diffuse Osteitis of the bones of the face and skull.-The bone in this disease presents a very different appearance from that which has just been described. There is no periosteal thickening, but the bone is expanded from within, and may reach a thickness of several inches. It is soft to cut and woolly in appearance, the $\mathrm{X}$-ray picture being not unlike Paget's disease of bone.

A. Generalised.- Stack quoted one such case in which the skull had been growing for twenty years. None of the foramina was affected, and there was no interference with brain or nerve function. "The head was of enormous weight, so that the patient had been accustomed to sit supporting it with her hands, so that in time her forefingers were dislocated outwards by the burden."

John Greene (junior), in an excellent monograph on the subject, quoted a case which he saw first in 1907 , and subsequently in 1914. He found marked improvement in the size of the skull during this time, the exophthalmos having receded to a remarkable extent, and the visual acuity remaining full, although latterly there was some optic atrophy and field loss.

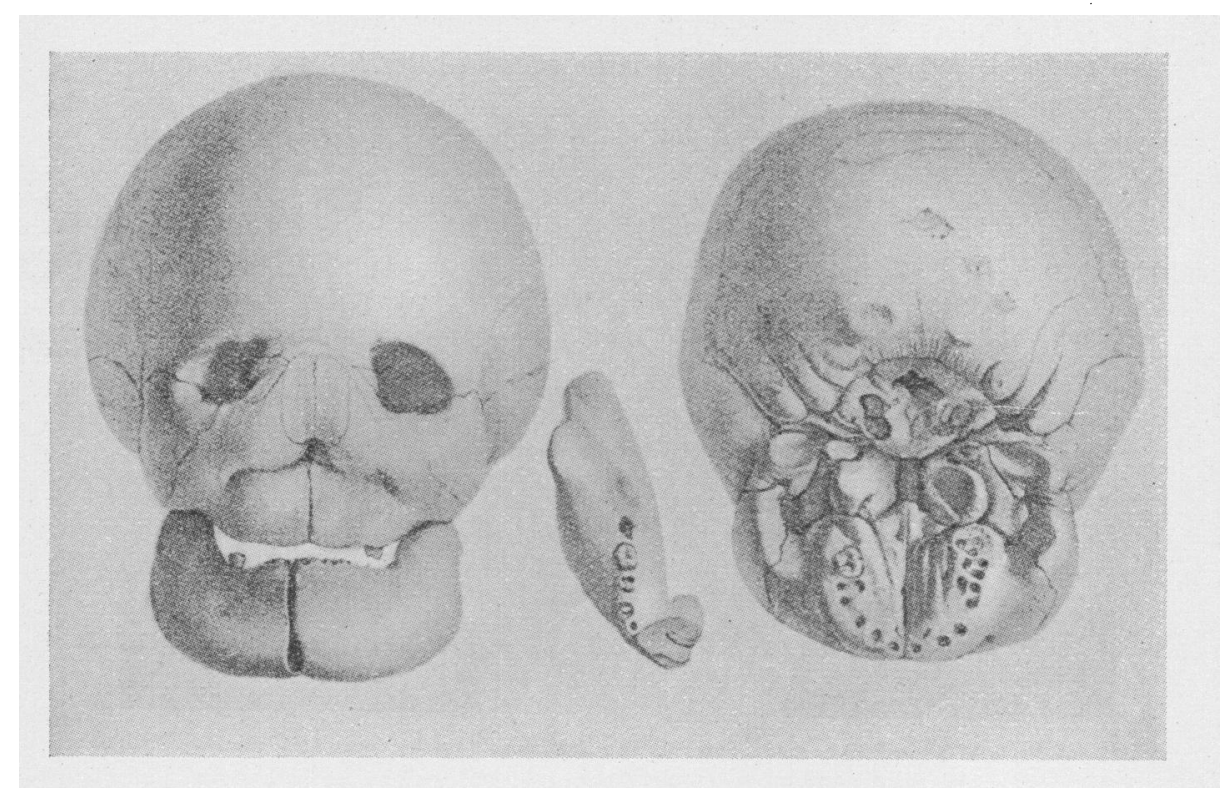

Fig. 3.

The Jadelot skull. By kind permission of R. Lawford Knaggs.

Fig. 3 is known as the Jadelot skull, and is that of a child of five. It shows the decrease in the size of the orbits, and consequent exophthalmos found in these patients. The skull was discovered 
by accident, and no clinical history is available. The ophthalmological complications of this condition are therefore exophthalmos and myopia in the early stages, and optic atrophy in the later.

B. Circumscribed Osteitis of one or more cranial bones.-In spite of the very marked cranial and facial changes in this group,

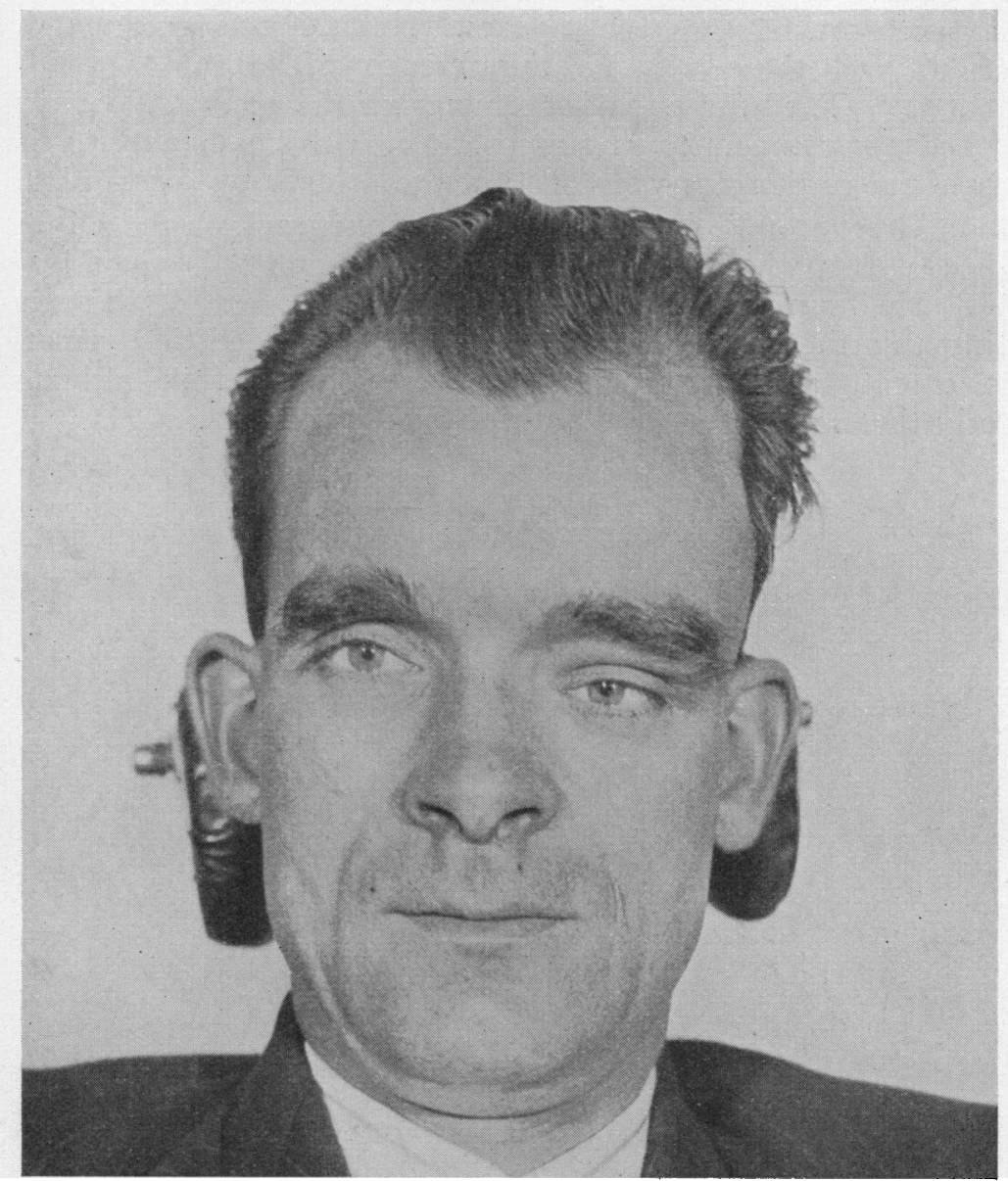

Fig. 4.

H. M. P., aged 33 years. To show the downward displacement of the left orbit.

ophthalmological complications are not common, and when they occur do so only in the later stages.

H. M. P., aged 33 years, male, was seen by the author in 
July, 1938, complaining of headaches. He had also noticed that the left side of his head was getting bigger.

History of the present condition.-The patient dated his troubles from a time fifteen years previously when he had suffered a motor accident, the top of the car coming down on his head. Examina-

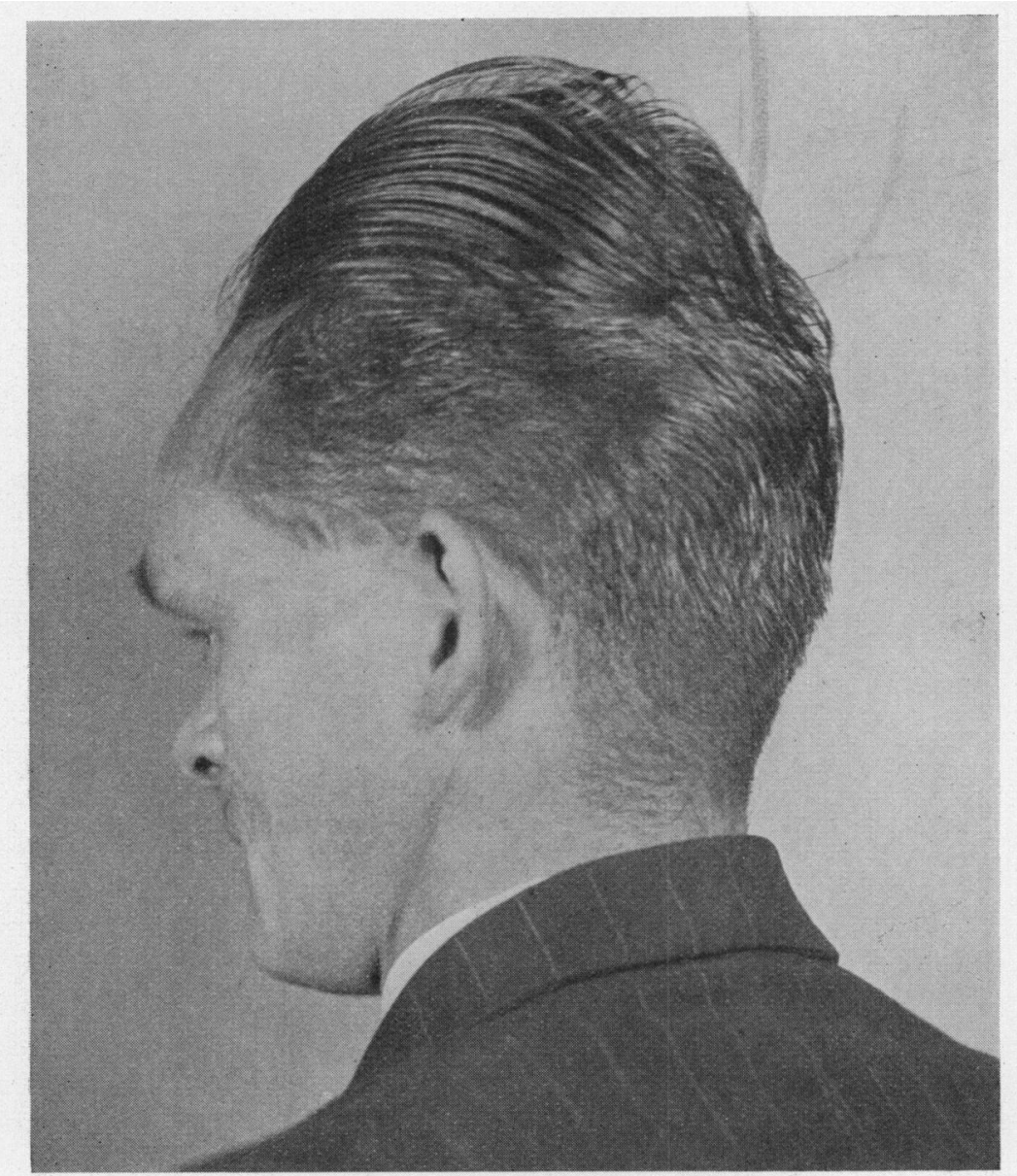

Fig. 5.

To show the overhanging brow. The large parietal exostosis has been covered over with hair.

tion of photographs taken eighteen years ago showed that there was marked bony deformity of the skull at that time, and thus the accident was probably in no way connected with the present condition. 


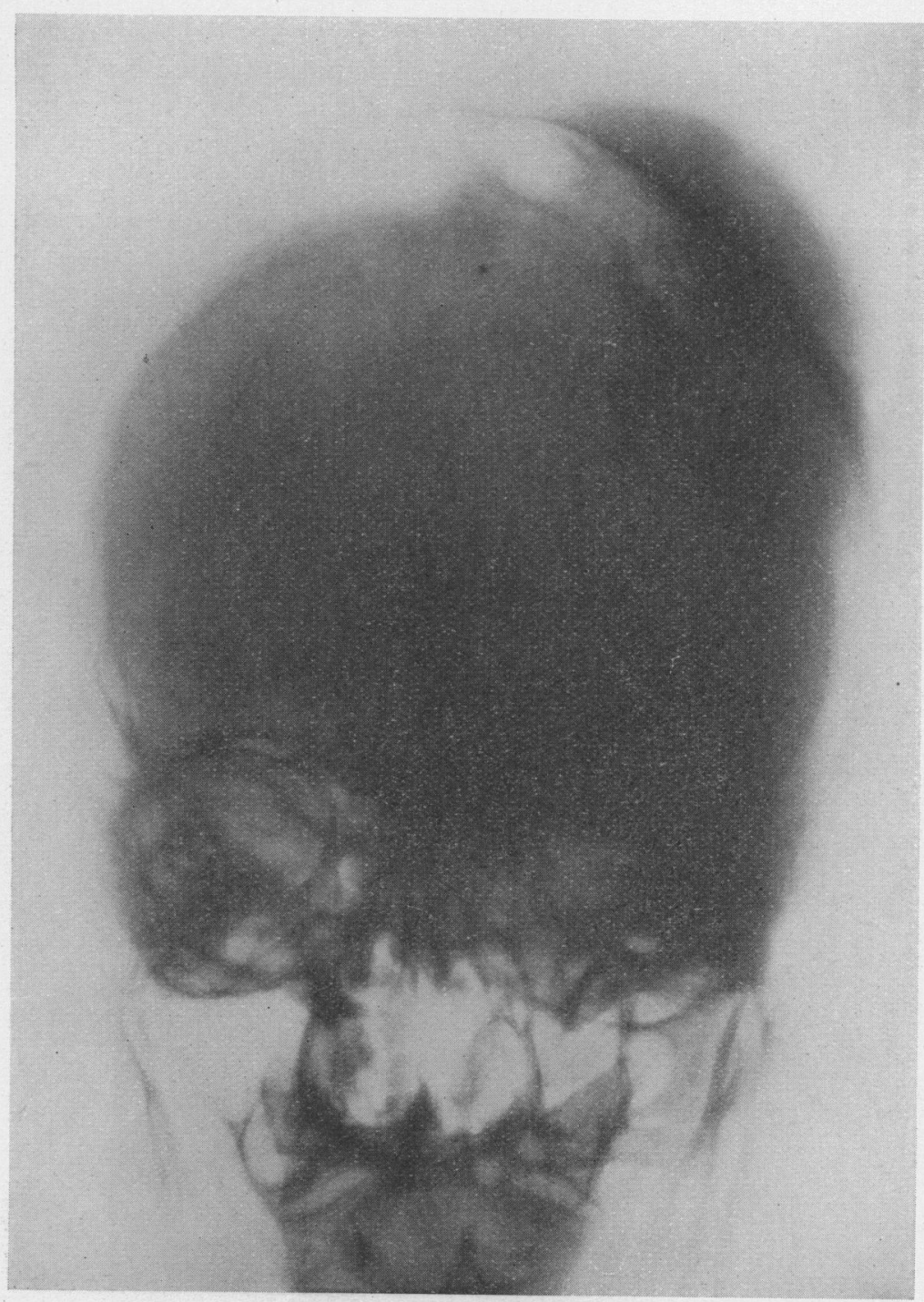

Fig. 6.

Showing the downward displacement of the left orbit and parietal exostosis.

Eleven years ago while in bed with 'flu, the doctor asked him what he had been doing to his head. This was the first reference he can remember to his condition, but it was very noticeable then and must have been present for many years before this. 
Six years ago he was examined at a hospital for left-sided headaches, and although there was then a marked bony swelling of the vault of the skull, he cannot remember that any reference was made to it, and certainly no investigations were carried out.

For some years now, he has had to buy a bigger size in hats each year, and for the past nine months has worn none, as it was painful to do so. By July, 1938, he had found that his headaches were so bad that he could not carry on with his work,

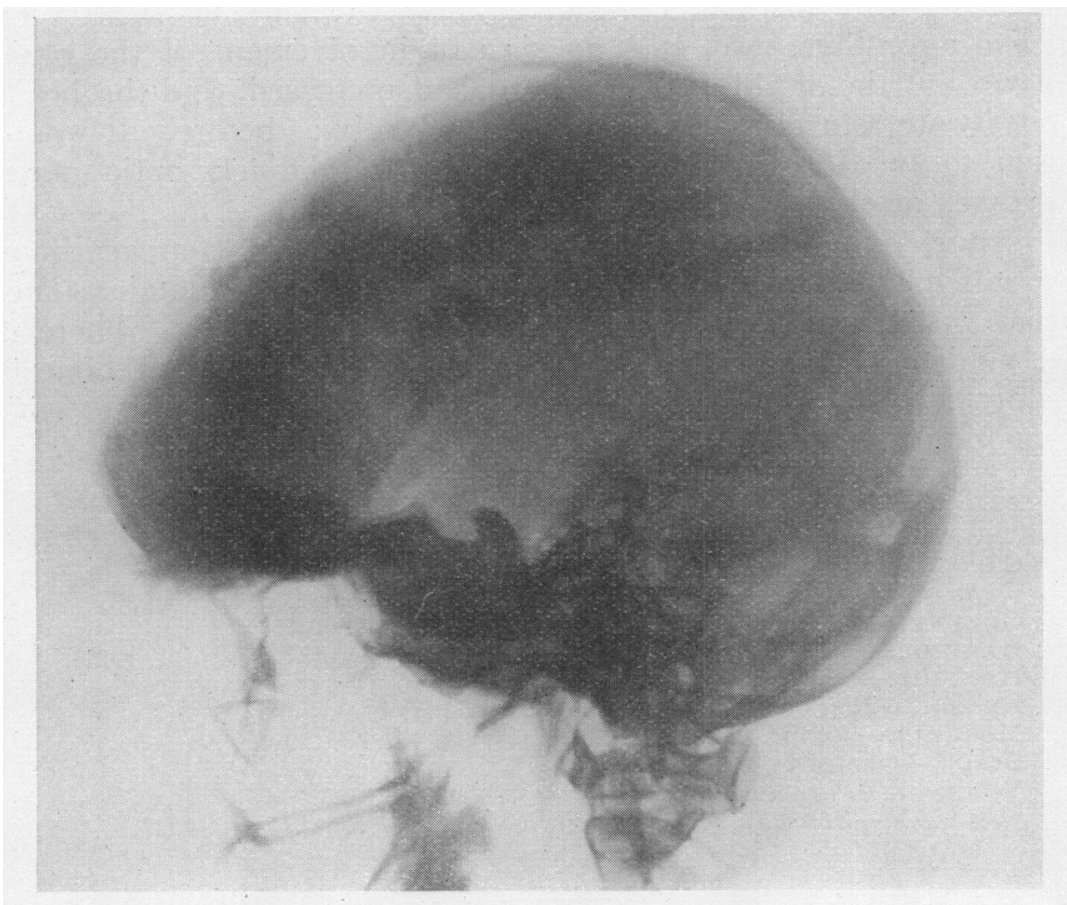

FIG. 7.

Lateral view of the skull. The filling in of the sphenoidal and other air sinuses is a characteristic of the disease.

and, as is so often the case with bony tumours, the pains troubled him chiefly at night.

Examination. There was a bony mass occupying the left parieto-occipital area, and also some thickening of the left frontal bone. This had caused the left orbit to be displaced downwards. The left eye was fifteen degrees convergent but all movements were full, the vision $6 / 6$, and the visual field normal. There was no proptosis, and no abnormality of the fundus or media of the eye. 
He was seen by Professor Paterson Ross, of St. Bartholomew's Hospital, who advised a linear osteotomy of the skull bones to relieve pain. This was done on August 22, 1938. The bone over the left parietal area was found to be between one and a half to two inches thick and very soft, but with no cysts. A longitudinal strip of bone half an inch wide was removed, and was followed by a marked improvement in the general condition of the patient, who was now free from headaches for the first time for a year. However, two months later he knocked his head, and following this his pains began again. When last seen some weeks ago, there was still no sign of involvement of the optic nerve, but the swelling of the head had increased, and the headaches were returning, though not so severely as before. It would seem to be only a matter of time before the left optic nerve becomes atrophic.

Report on bone remored. The sections show compact bone in which the Haversian canals are enlarged and contain somewhat vascular fibrous tissue which is almost acellular. There is no evidence of lacunar resorption of bone, and no new bone is being laid down. The appearance of the bone is consistent with that found in osteitis fibrosa.

\title{
BIBLIOGRAPHY
}

CaPon.-Archiv. Dis. Child., Vol III, p. 285, 1928.

Chambers.-Proc. Roy. Soc. Med., Vol. XXIII, Part 2, p. 1006, 1930.

Greene.-Amer. Jl Ophthal., Vol. XXXII, p. 293, 1915.

Harman.-Proc. Roy. Soc. Med., Sect. Ophthal., Vol. XIV, p. 11, 1921.

Howship.-Observations in Surgery, 1819.

KNAGgs.-Brit. Jl. of Surgery, Vol. II, p. 347, 1923.

MORELli.-Annal. ai Ottal., Vol. LIII, pp. 773-787, 1925.

STACK.-Quoted by Harman.

VIRchow.-Pathologie des Tumeurs, Vol. XXI, 1896.

von PAAs.-Zeitschr. $f$. Augenheilk., Vol. XCII, pp. 221-230, 1937.

\section{CULTURE IN VITRO OF THE CORPUSCLES OF TRACHOMA}

\author{
BY \\ DR. L. POLEFF \\ INSTITUT D'HYGIENE DU MAROC
}

IN his comprehensive report on the aetiology of trachoma MacCallan concludes that the causal agent of this infection is certainly a virus. The group of minute organisms to which it belongs is characterized by the following features: (1) The formation of intracellular inclusions in the tissues affected by the 